\title{
Hyperglycemia Induced Apoptosis Changes in Salivary Gland Cells of Mice
}

\author{
Bo Hyun Jung \\ Departments of Anatomy and Research Institute of Oral Science, Gangneung-Wonju National University College of Dentistry, \\ Gangneung, Korea \\ Email: jbh3214@gmail.com
}

How to cite this paper: Jung, B.H. (2021) Hyperglycemia Induced Apoptosis Changes in Salivary Gland Cells of Mice. Journal of Biosciences and Medicines, 9, 143-157. https://doi.org/10.4236/jbm.2021.93013

Received: February 22, 2021

Accepted: March 28, 2021

Published: March 31, 2021

Copyright (c) 2021 by author(s) and Scientific Research Publishing Inc. This work is licensed under the Creative Commons Attribution International License (CC BY 4.0).

http://creativecommons.org/licenses/by/4.0/

\begin{abstract}
If the function of salivary glands that secrete saliva is degraded, saliva secretion will decrease and symptoms of xerostomia will appear. Although symptoms of xerostomia are often felt by patients with diabetes, the relationship between diabetes and xerostomia is currently unclear. In relation to DM, there are studies on salivation flow and saliva composition, but there are not studies of apoptosis of salivary gland cells. The objective of this study was to investigate whether apoptosis in salivary glands of mice with hyperglycemic, a symptom of diabetes, might be altered based on immunohistochemical analysis. This study used mice with hyperglycemia. Immunohistochemistry and Western blot analyses were performed using Fas, Bax, and cleaved caspase-3 antibodies. These antibodies are used not only as death receptors, but also are antibodies that activate upstream and downstream signals of apoptosis. TUNEL assay was performed to detect apoptosis by immunofluorescence using TdT enzyme. It was observed that the expression level of apoptosis signaling molecules and TUNEL positive cells were increased in hyperglycemia group (HG). As a result, there are many apoptosis cells in the HG groups of the salivary gland. The results of this study, the function of salivary gland could occur deteriorated due to apoptosis on salivary gland cells by hyperglycemic, a characteristic of diabetes.
\end{abstract}

\section{Keywords}

Salivary Gland, Hyperglycemic, Apoptosis, Hyposalivation, Diabetes

\section{Introduction}

Diabetes is divided into type 1 diabetes due to insulin deficiency and type 2 diabetes due to the inability to maintain blood glucose homeostasis. The disease is mainly characterized by hyperglycemia [1] [2]. Among the oral complication of 
diabetes, characterized by hyperglycemia, is xerostomia. Xerostomia can reduce saliva secretion and cause unhealthy effects in the oral cavity [3] [4].

Saliva has a variety of functions in the oral cavity. The most important function of saliva is its ability to protect the oral cavity by inhibiting the growth of bacterial plaque. It also provides a buffer function to protect the teeth by preventing demineralization. Saliva also contains antibacterial proteins in the oral cavity. In addition, amylase, a digestive enzyme in saliva, can dissolve food and help the digestion process. It can transfer the dissolved substance to the taste bud so that the taste of dissolved food can be sensed [5].

On the other hand, diabetic people often feel symptom of xerostomia [6]. It was suggested that salivary glands are degeneration, resulting in decreased saliva flow, resulting in xerostomia in diabetics [7]. However, a clear mechanism of this has not been determined. The intracellular mechanism of xerostomia, which is a symptom of DM, has not been clearly determined. Experiments on the reduction of salivation associated with DM have been reported [8]. After comparing saliva compositions between type 2 diabetic patients and normal people, glucose and potassium levels in diabetic patients were found to be significantly higher in DM patients than those in normal people while salivary flow rate in DM patients was significantly lower than that in normal people [8]. Sandberg GE et al. (1970) have reported that oral dryness symptom of type 2 diabetic patients is significantly higher than that in normal people [6]. In addition, it is reported that a study showing morphological changes in the intralobular duct of the salivary gland due to hyperglycemia has been reported [9].

It was reported that function of salivary glands and salivation decreased due to apoptosis of salivary glands cells caused by head and neck radiation therapy [10] [11]. In this study, it was considered whether hyposalivation due to diabetes was due to apoptosis of salivary gland cells. There are studies comparing the flow, saliva composition and morphology in relation to DM [8] [12] [13] [14]. However, there are no studies comparing the apoptosis of the salivary gland cell. Therefore, this study tried to performed whether apoptosis in salivary gland cells caused by hyperglycemia, a characteristic of diabetes.

\section{Materials and Method}

\subsection{Experimental Animal}

C57BL/6 mice (5-week-old, 17 - 18 g body weight) and Male $\mathrm{db} / \mathrm{db}$ mice (5-week-old, 30 - $32 \mathrm{~g}$ body weight), purchased from Orient Bio (Seongnam, Korea), were used for this study. The animals were maintained at $22^{\circ} \mathrm{C}$ of temperature and $50 \%$ of humidity and were feeded freely 12 hours of day/night cycle. All the procedures of this study were carried out according to the standard work guidelines, with approval (Approval No. GWNU-2016-18) of the Institutional Animal Care and Use Committee of Gangneung-Wonju National University.

The control group used the C57BL/6 mice. And the experimental group used 
the $\mathrm{db} / \mathrm{db}$ mice because it is hyperglycemic mice. The experimental group was divided into 8,10 and 12 weeks based on 4 - 5 weeks when blood glucose started to rise [15]. In this study, 7 animals $(n=7)$ were used for each experimental group. The groups are as follows.

1) Control groups: CTL $8 \mathrm{~W}, 10 \mathrm{~W}$ and $12 \mathrm{~W}$ group.

2) Hyperglycemia groups (HG): HG $8 \mathrm{~W}, 10 \mathrm{~W}$ and $12 \mathrm{~W}$ group.

\subsection{Western Blot}

For western blot analysis, the parotid and submandibular glands were excised under anesthesia. Excised tissues were stored in the deep freezer $\left(-70^{\circ} \mathrm{C}\right)$ until using.

The prepared tissues were homogenized with $180 \mu$ lysis buffer ( $\mathrm{pH} 7.5$, containing $137 \mathrm{mM} \mathrm{NaCl}, 20 \mathrm{mM}$ Tris- $\mathrm{HCl}, 1 \%$ Tween 20, 10\% Glycerol, $1 \mathrm{mM}$ Phenylmethylsulfonyl fluoride and protease inhibitor cocktail) at $0^{\circ} \mathrm{C}$ for 30 minutes. Each sample was centrifuged by destroying the cells using an ultrasonicator at $15,000 \mathrm{rpm}$ and $4^{\circ} \mathrm{C}$ for 30 minutes, and the supernatant was centrifuged again. The proteins of the isolated tissue samples were mixed with the same amount of $2 \times$ loading buffer $20 \mu$ of protein mixtures were electrophoresed in $12 \%$ polyacrylamide gel. The electrophoresed protein was put into a cassette and transferred to the nitrocellulose membranes (Pall Crop, EastHills, $\mathrm{NY}$ ) at $250 \mathrm{~mA}$ for 1 hour. After transfer, the membrane was blocked with $5 \%$ skim milk and then washed with $10 \times$ Tris buffer saline with Tween 20 (TBST) buffer ( $\mathrm{pH}$ 7.6). The primary antibodies, rabbit anti-Fas (diluted 1:1000, Abcam. Cambridge, UK), rabbit anti-Bax (diluted 1:1000, SantacrusBip. Dallas, USA) and rabbit anti-Cleaved Caspase-3 (diluted 1:1000, SantacruzBip. Dallas, USA) were added to the washed membrane and incubated at room temperature for 1 hour. Then, the membrane was washed three times for 10 minutes with TBST buffer ( $\mathrm{pH}$ 7.6). The biotinylated secondary antibody, goat anti-rabbit IgG (VECTOR, California, USA), was added to the washed membrane according to the primary antibodies and shaken for 1 hour. After wash the membrane three times for 10 minutes with TBST buffer ( $\mathrm{pH}$ 7.6), the washed membrane was detected using X-ray film.

\subsection{Immunohistochemistry}

For immunohistochemical analysis, the animals were anesthetized. Then, the animals were perfused intracardially with $0.9 \%$ saline and $4 \%$ paraformaldehyde in phosphate buffered saline ( $\mathrm{pH}$ 7.5). The parotid and submandibular glands were excised and postfixed with same fixative for 8 hours.

Then, paraffin blocks were prepared by dehydration, transparency and paraffin infiltration in an automatic processor (Leica, Nussloch, Germany) to produce paraffin blocks and paraffin sections (Leica RM2255, Nussloch, Germany) of 5 $\mu \mathrm{m}$ were prepared and attached to saline-coated slides (MYTO, Tokyo, Japan) for tissue staining. 
The salivary gland tissues were washed twice with xylene for 10 minutes to remove paraffin and then dehydrated through ordinary dehydration processes. After dehydration, the tissues were washed three times for 10 minutes with 0.01 $\mathrm{M}$ PBS ( $\mathrm{pH}$ 7.3) and antigen retrieval was performed for 10 minutes using microwave in citrate buffer ( $\mathrm{pH}$ 6.0). After the antigen retrieval, the citrate buffer ( $\mathrm{pH}$ 6.0) was completely cooled and then washed three times with $0.01 \mathrm{M}$ PBS ( $\mathrm{pH}$ 7.3) for 10 minutes. The tissues were treated with 0.01 M PBS (pH 7.3) solution containing $3 \%$ hydrogen peroxide $\left(\mathrm{H}_{2} \mathrm{O}_{2}\right)$ for 30 minutes and then washed three times with $0.01 \mathrm{M}$ PBS (pH 7.3) for 10 minutes. After washing, 0.01 M PBS $(\mathrm{pH}$ 7.3) containing $5 \%$ normal goat serum sprayed on the tissues and treated for 10 minutes. Do not wash the treated tissues. After shaking out the reaction solution, spray 0.01 M PBS ( $\mathrm{pH} 7.3$ ) solution containing rabbit anti-Fas (diluted 1:50, Abcam. USA), rabbit anti-Bax (diluted 1:250, SantacrusBip., Dallas, USA) and rabbit anti-Cleaved Caspase-3 (diluted 1:200, SantacrusBip., Dallas, USA). Cover the sealing film on the slides so that the solution and tissue do not dry out and treat them at $4^{\circ} \mathrm{C}$ for one day. After treatment, the slides were washed three times with $0.01 \mathrm{M} \mathrm{PBS}$ ( $\mathrm{pH}$ 7.3) for 10 minutes. Biotinylated rabbit anti-goat was diluted 1:250 in 0.01 M PBS ( $\mathrm{pH}$ 7.3) and applied to slides for 120 minutes. After the reaction, the tissues were washed three times for 10 minutes with $0.01 \mathrm{M}$ PBS (pH 7.3) and then reacted with Avidin-biotin complex (ABC) kit (VECTOR, California, USA) for 90 minutes. After the reaction, the tissues are washed three times for 10 minutes in $0.01 \mathrm{M} \mathrm{PBS}(\mathrm{pH}$ 7.3). After washed tissues were color reaction using a solution of $250 \mu \mathrm{l}$ of 1\% 3,3-diaminobenzidine (DAB) (Sigma, St. Louis, USA) and $0.3 \% \mathrm{H}_{2} \mathrm{O}_{2}$ in $5 \mathrm{ml}$ of $0.01 \mathrm{M} \mathrm{PBS} \mathrm{(pH} \mathrm{7.3)} \mathrm{and} \mathrm{then} \mathrm{wash}$ with distilled water three times for 10 minutes. After that, dehydration and clarification process were carried out and sealed with Canada balsam (Kanto, Tokyo, Japan). Completed slides were observed under a microscope (Axio Imager A2, Carl Zeiss, Göttingen, Germany).

\subsection{Terminal Deoxynucleotidyl Transferase dUTP Nick End Labeling (TUNEL)}

In this study, TUNEL staining was performed to confirm the cell death of the salivary gland cells by DM. It was performed using TUNEL Kit (Promega, Madison, USA). The salivary gland tissues were washed twice with xylene for $10 \mathrm{mi}-$ nutes to remove paraffin. After the paraffin was removed, the tissues were treated with $100 \%$ ethanol for 5 minutes twice, followed by a normal hydration procedure. The tissues were washed in $0.01 \mathrm{M} \mathrm{PBS}$ ( $\mathrm{pH}$ 7.3) for 5 minutes. The tissues were fixed in $4 \%$ formaldehyde in PBS for 4 minutes and then washed twice with $0.01 \mathrm{M}$ PBS (pH 7.3) for 5 minutes. To increase the permeability of the tissues, $20 \mu \mathrm{g} / \mathrm{ml}$ proteinase $\mathrm{K}$ dissolved in proteinase $\mathrm{K}$ buffer was applied to the slide to cover the tissues completely and treated at room temperature for 10 minutes. After the reaction, the tissues were washed with $0.01 \mathrm{M}$ PBS ( $\mathrm{pH}$ 7.3) for 5 minutes. Afterwards, the reaction was terminated by treatment with $4 \%$ formaldehyde for 5 minutes. The fixed tissues were again washed with $0.01 \mathrm{M}$ 
PBS (pH 7.3) for 5 minutes. The pretreated tissues were mixed with Equilibrate buffer: nucleotide mix: $\mathrm{rTdT}$ at a ratio of 90:10:2 and the mixture was sprayed with $50 \mu \mathrm{l}$ per slide and reacted at $37^{\circ} \mathrm{C}$ for 1 hour. After the reaction was completed, the reaction solution was shaken off and $2 \times$ saline sodium citrate (SSC) diluted in distilled water was treated for 15 minutes to complete the reaction. The treated tissues were washed with 0.01 M PBS ( $\mathrm{pH}$ 7.3) for 5 minutes three times, finally washed with distilled water for 5 minutes, completely dried in an oven at $50^{\circ} \mathrm{C}$, dipped in xylene for 2 minutes and sealed with dibutyl phthalate xylene (DPX) (Sigma, St. Louis, USA). The completed slides were observed under a fluorescence microscope (Axio Imager A2, Zeiss, Germany) at a wavelength of Ex: $385 \mathrm{~nm}$ and Em: $425 \mathrm{~nm}$.

\subsection{Data Analysis and Statistical Processing}

The most common sites of stained tissues were photographed using a microscope (Axio Imager A2, Zeiss, Germany) equipped with a CCD camera. The number of TUNEL positive cells was counted in similar part of 5 sections per experimental animal, and the average value was calculated.

The values shown in this study were expressed as mean \pm SEM. The difference between the two groups was statistically analyzed using the Mann-Whitney U test and One-sample $\mathrm{T}$ test. Statistical significance was considered significant if the p-value was less than 0.05 .

\section{Results}

\subsection{Blood Glucose Level}

Blood glucose was measured from 5 to 12 weeks. After 5 weeks, blood glucose was steadily rising (Figure 1).

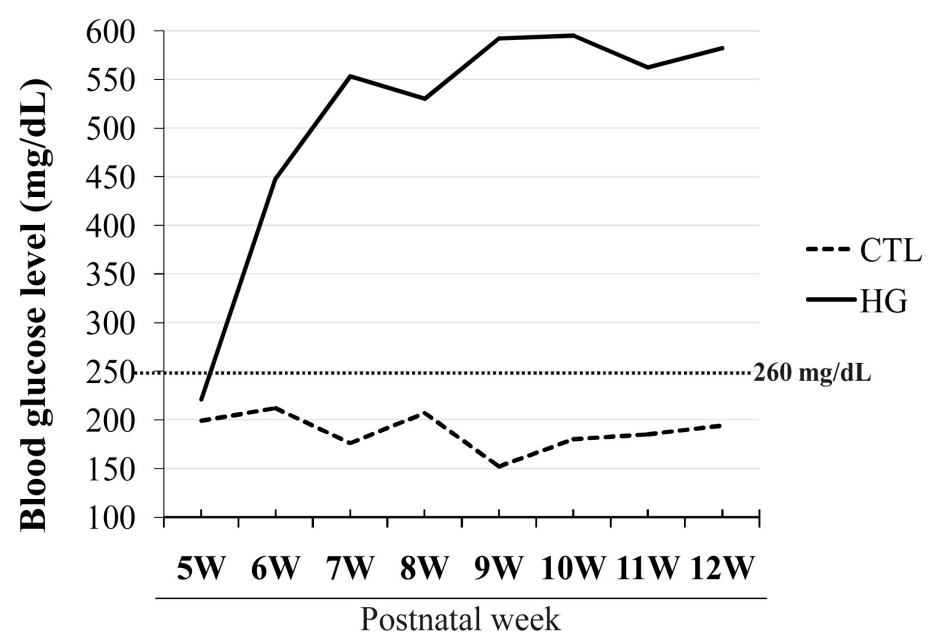

Figure 1. Evaluation of blood glucose level in mice. In the CTL group, blood glucose levels of mice were about $200 \mathrm{mg} / \mathrm{dL}$. However, in the HG group, it exceeded $260 \mathrm{mg} / \mathrm{dL}$ after postnatal 6 weeks. Generally, diabetes mellitus means that the blood glucose maintained more than $260 \mathrm{mg} / \mathrm{dL}$. The bars indicate the means \pm SEM. 


\subsection{Submandibular Gland}

1) Immunohistochemistry

To confirm apoptosis in salivary gland cells, immunohistochemical staining was performed using Fas, Bax, and Cleaved Caspase-3 antibodies. Fas antibody, which is mainly used as death receptor according to apoptosis activity stage. Bax and Cleaved Caspase- 3 antibodies that activates up-stream and down-stream of apoptosis signal in mitochondria.

Results of immunohistochemistry by using Fas, Bax and cleaved caspase- 3 antibody, it was observed that more immunoreactive cells in the HG groups than those in the CTL groups. In the HG groups, immunoreactive cells were mainly observed in the acinar cell (Figures 2(A)-(I), Figures 2(a)-(i)).

Especially, immunoreactive cells were more observed in the HG 10 weeks group (Figure 2(b), Figure 2(e) and Figure 2(h)).

\section{2) Western blot}

To confirm apoptosis, western blot analysis was performed to determine protein expression level. Western blot analysis was performed using antibody against Fas, as apoptotic activating receptor protein and antibodies against Bax and cleaved caspase- 3 as, pro-apoptotic protein. The amount of expression of these apoptotic signal molecules in each CTL groups were determined as the absolute value 1 by using the amount of $\beta$-actin expression. These values were compared with their expression level in the HG groups.

All the HG groups showed higher increase in expression of these apoptotic signal molecules than the CTL groups. The difference in the amount of expression of apoptotic signal molecules between the CTL groups and the HG groups were statistically significant (Figure 3).

The amount of expression of Fas was the highest at about 9.75 level in the HG 10 weeks group, and the lowest at about 3.93 level in the HG 8 weeks group. In the HG 12 weeks group was observed about 4.88 level. The amount of expression of Bax was the highest at about 8.96 level in the HG 10 weeks group, and it observed as low as at about 4.79 level in the HG 8 weeks group and HG 12 weeks

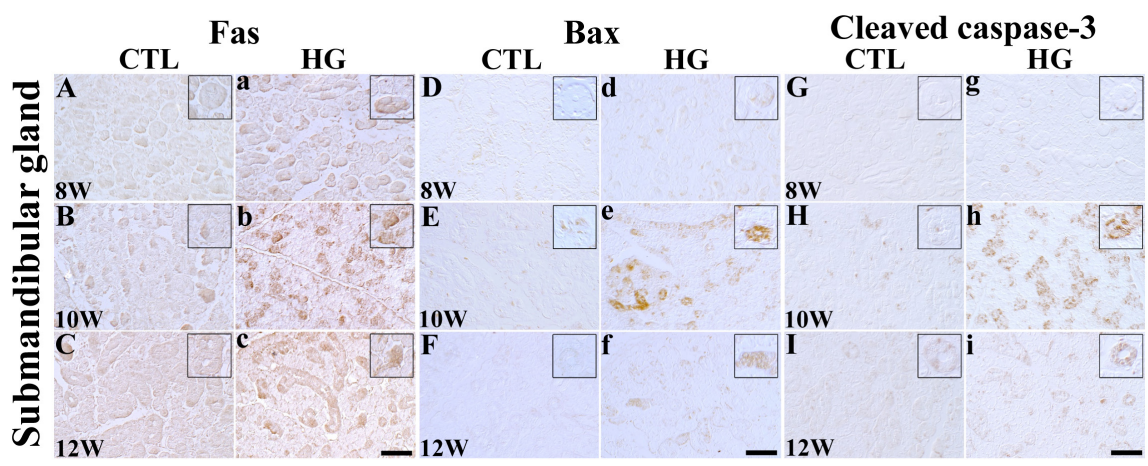

Figure 2. Immunohistochemistry of Fas, Bax and Cleaved caspase-3 in the submandibular gland of the CTL and HG groups. 200×. Scale Bar $=100 \mu \mathrm{m}$. (a)-(i) In the HG group, many Fas, Bax and Cleaved caspase- 3 positive cells are mainly observed in acinar cells of the submandibular gland than (A)-(I) in the CTL groups. 

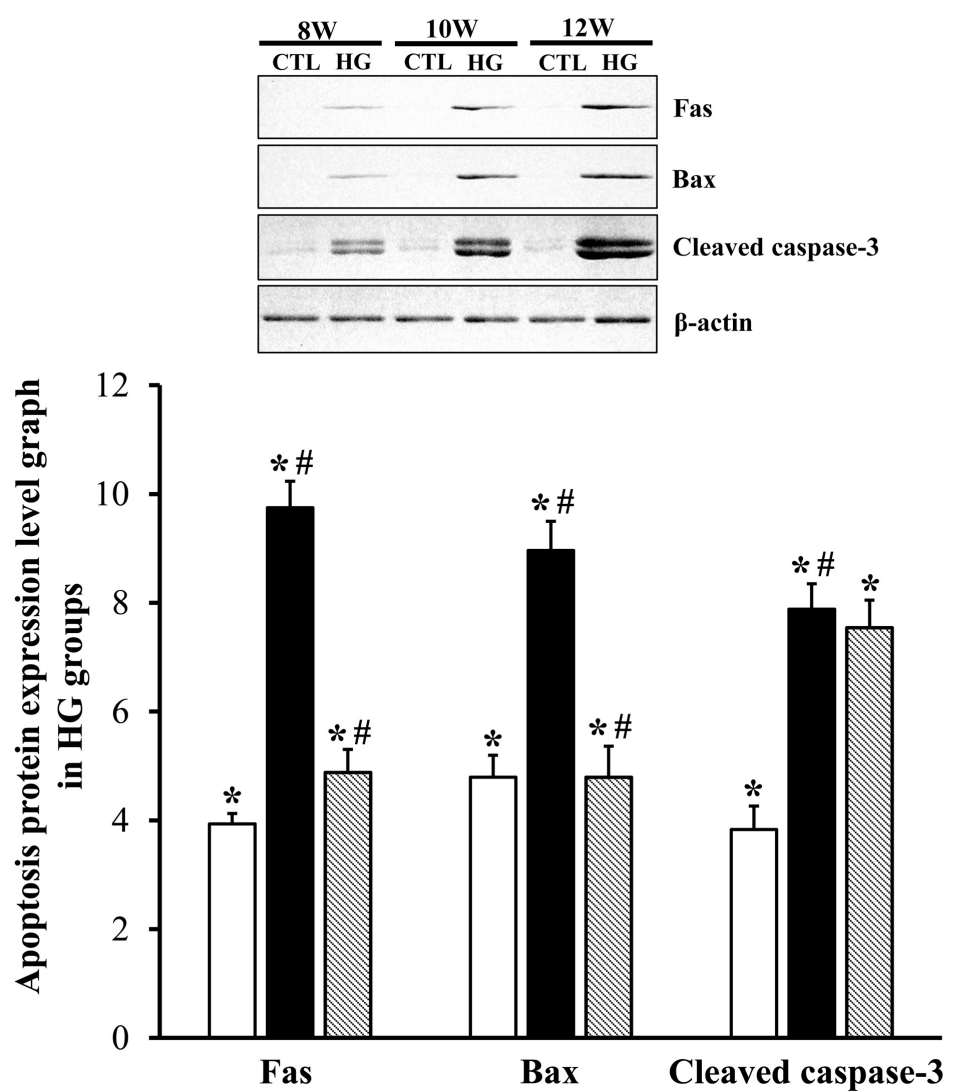

Figure 3. Western blot analysis of Fas, Bax and Cleaved caspase-3 in the submandibular gland of the control and HG groups. It was observed that protein expression increased in the HG groups. Apoptosis protein expression level comparative graph in the submandibular gland. ( $n=7$ per group; ${ }^{\star} P<0.05$, significantly different from the CTL group, ${ }^{\sharp} P<$ 0.05 , significantly different from the pre-adjacent HG group). The bars indicate the means \pm SEM.

group. The amount of expression of Fas and Bax were statistically significantly increased in the HG 10 weeks group and the HG 12 weeks group compared to the pre-adjacent HG groups. The amount of expression of cleaved caspase- 3 was the highest at about 7.88 level in the HG 10 weeks group, and the lowest at about 3.83 level in the HG 8 weeks group. In the HG 12 weeks group was observed about 7.54 level. The amount of expression of cleaved caspase- 3 was statistically significantly increased in the HG 10 weeks group compared to the pre-adjacent HG group, but not the HG 12 weeks group (Figure 3).

3) Terminal deoxynucleotidyl transferase dUTP nick end labeling (TUNEL)

To confirm fragmentation of DNA during apoptosis due to diabetes, TUNEL assay was carried out by binding nucleotides through TdT enzyme and detecting immunofluorescence.

It was observed that the number of TUNEL positive cells was higher in the HG groups than that in the CTL groups. There was no difference in the number of TUNEL positive cells among the CTL groups. In the HG groups, the number 
of TUNEL positive cells was increased since the HG 10 weeks group (Figures 4(A)-(C), Figures 4(a)-(c)).

The results of the number of TUNEL positive cells were shown in Table 1.

Results of cell count in parotid gland, the difference in the number of apoptotic cells between the CTL 8 weeks group and the HG 8weeks group was not statistically significant. In the HG 10 weeks group, the number of apoptotic cells were increased of $75.65 \%$ compared with the CTL 10 weeks group. In the HG 12 weeks group, the number of apoptotic cells were increased of $58.26 \%$ compared with the CTL 12 weeks group. The number of TUNEL positive cells in the HG 10 weeks group was also significantly higher than that in the HG 8 weeks group and pre-adjacent group (Figure 4(D)).

\subsection{Parotid Gland}

\section{1) Immunohistochemistry}

To confirm apoptosis in salivary gland cells, immunohistochemical staining was performed using Fas, Bax, and Cleaved Caspase-3 antibodies. Fas antibody, which is mainly used as death receptor according to apoptosis activity stage. Bax and Cleaved Caspase- 3 antibodies that activates up-stream and down-stream of apoptosis signal in mitochondria.
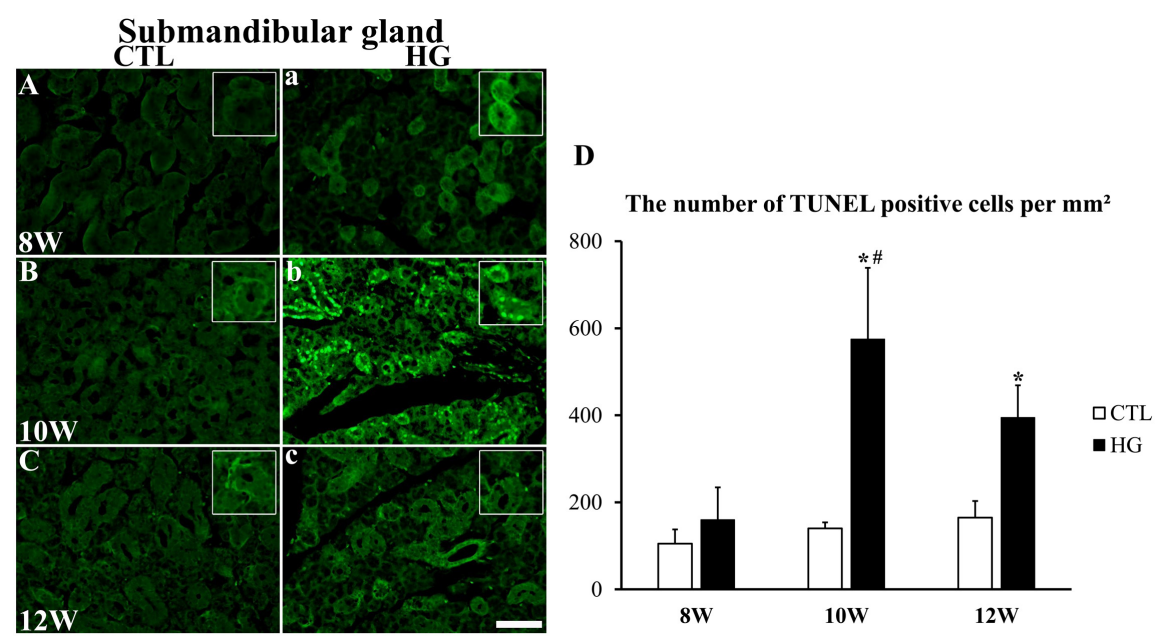

Figure 4. TUNEL stain in the submandibular gland of the CTL and HG groups. 200×. Scale Bar $=100 \mu \mathrm{m}$. (a)-(c) In the HG group, TUNEL positive apoptotic cells are mainly observed in acinar cells of the submandibular gland than (A)-(I) in the CTL groups. (D) The number of TUNEL positive cells in the submandibular gland of the CTL and HG group. ( $n=7$ per group; ${ }^{\star} P<0.05$, significantly different from the CTL group, ${ }^{\sharp} P<0.05$, significantly different from the pre-adjacent HG group). The bars indicate the means \pm SEM.

Table 1. The number of positive cells $\left(\right.$ cells $\left./ \mathrm{mm}^{2}\right)$ in submandibular gland.

\begin{tabular}{cccc}
\hline CTL 8 weeks & $105 \pm 32.596$ & HG 8 weeks & $160 \pm 74.161$ \\
CTL 10 weeks & $140 \pm 13.693$ & HG 10 weeks & $575 \pm 163.936$ \\
CTL 12 weeks & $165 \pm 37.914$ & HG 12 weeks & $395 \pm 73.739$ \\
\hline
\end{tabular}


Results of immunohistochemistry by using Fas, Bax and cleaved caspase- 3 antibody, it was observed that more immunoreactive cells in the HG groups than those in the CTL groups. In the HG groups, immunoreactive cells were mainly observed in the acinar cell (Figures 5(A)-(I), Figures 5(a)-(i)).

Especially, immunoreactive cells were more observed in the HG 12 weeks group (Figure 5(b), Figure 5(e) and Figure 5(h)).

\section{2) Western blots}

To confirm apoptosis, western blot analysis was performed to determine protein expression level. Western blot analysis was performed using antibody against Fas, as apoptotic activating receptor protein and antibodies against Bax and cleaved caspase- 3 as, pro-apoptotic protein. The amount of expression of these apoptotic signal molecules in each CTL groups were determined as the absolute value 1 by using the amount of $\beta$-actin expression. These values were compared with their expression level in the HG groups.

All the HG groups showed higher increase in expression of these apoptotic signal molecules than the CTL groups. The difference in the amount of expression of apoptotic signal molecules between the CTL groups and the HG groups were statistically significant (Figure 6).

The amount of expression of Fas was the highest at about 5.77 level in the HG 12 weeks group, and the lowest at about 4.30 level in the HG 8 weeks group. In the HG 10 weeks group was observed about 4.96 level. The amount of expression of Fas was not statistically significantly increased in all HG groups compared to the pre-adjacent HG groups. The amount of expression of Bax was the highest at about 7.02 level in the HG 12 weeks group, and the lowest at about 3.59 level in the HG 8 weeks group. In the HG 10 weeks group was observed about 5.18 level. The amount of expression of cleaved caspase- 3 was the highest at about 14.24 level in the HG 12 weeks group, and the lowest at about 3.75 level in the HG 8 weeks group. In the HG 10 weeks group was observed about 5.66 level. The amount of expression of Bax and cleaved caspase- 3 were statistically significantly increased in the HG 10 weeks group and the HG 12 weeks group compared to the

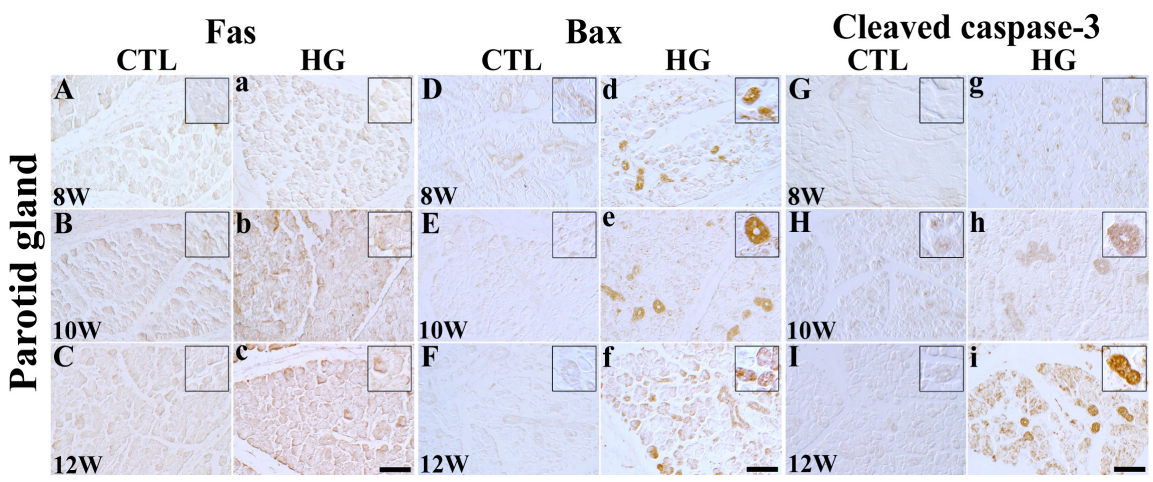

Figure 5. Immunohistochemistry of Fas, Bax and Cleaved caspase- 3 in the parotid gland of the CTL and HG groups. 200×. Scale Bar $=100 \mu \mathrm{m}$. (a)-(i) In the HG group, many Fas, Bax and Cleaved caspase- 3 positive cells are mainly observed in acinar cells of the parotid gland than (A)-(I) in the CTL groups. 


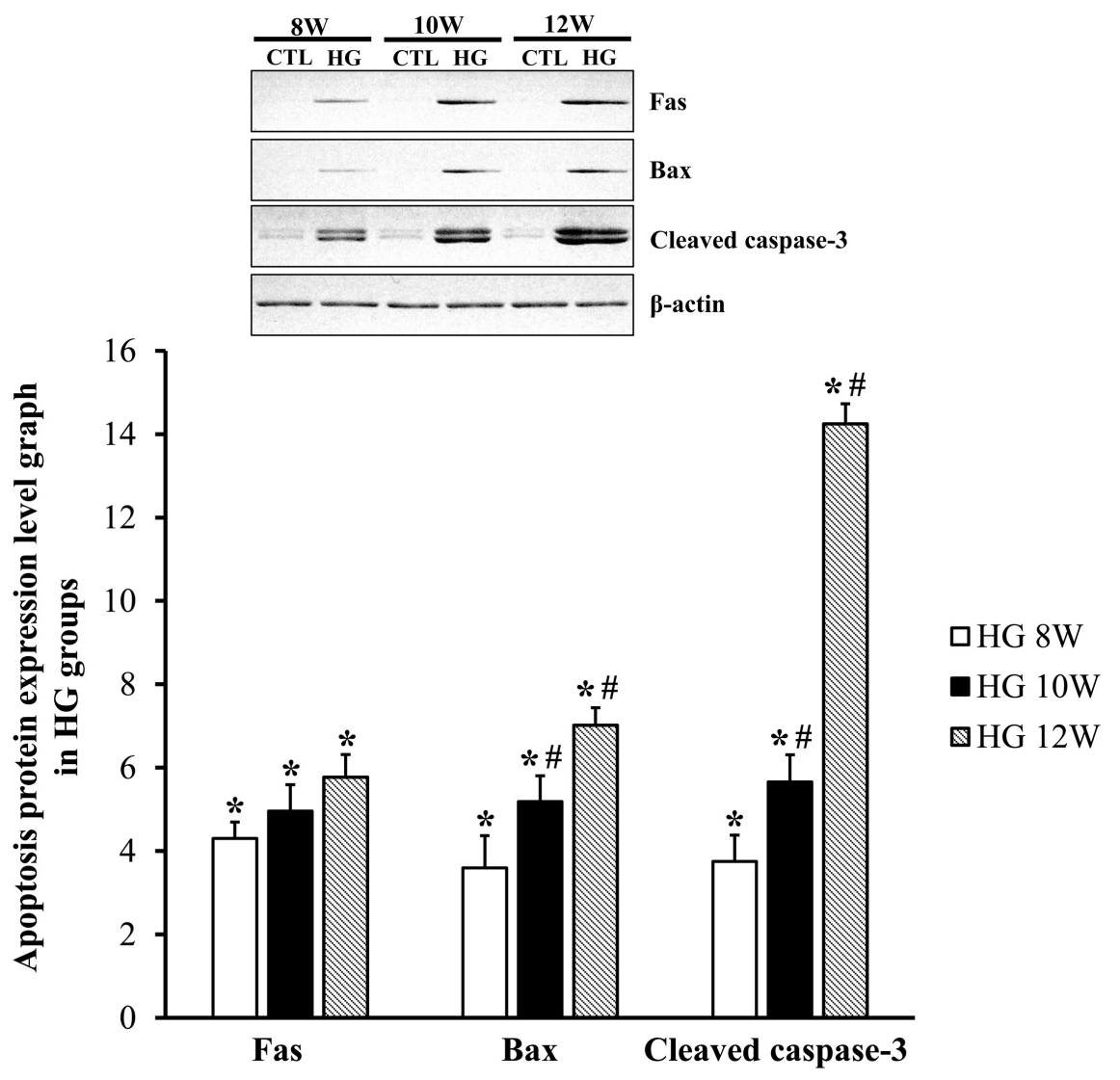

Figure 6. Western blot analysis of Fas, Bax and Cleaved caspase-3 in the parotid gland of the control and HG groups. It was observed that protein expression bands were thick in the HG groups. Apoptosis protein expression level comparative graph in the Parotid gland. ( $n=7$ per group; ${ }^{\star} P<0.05$, significantly different from the CTL group, ${ }^{\sharp} P<0.05$, significantly different from the pre-adjacent HG group. The bars indicate the means \pm SEM.

pre-adjacent HG groups (Figure 6).

3) Terminal deoxynucleotidyl transferase dUTP nick end labeling (TUNEL)

To confirm fragmentation of DNA during apoptosis due to diabetes, TUNEL assay was carried out by binding nucleotides through TdT enzyme and detecting immunofluorescence.

The number of TUNEL positive cells in the HG group was higher than that in the CTL group. Numbers of TUNEL positive cells in the CTL 10 weeks group and the CTL 12 group were higher than those in the pre-adjacent group (Figures 7(A)-(C), Figures 7(a)-(c)).

The results of the number of TUNEL positive cells were shown in Table 2.

Results of cell count in parotid gland, in the HG 8 weeks group, the number of apoptotic cells were increased of $73.94 \%$ compared with the CTL 8 weeks group. In the HG 10 weeks group, the number of apoptotic cells were increased of 20.192\% compared with the CTL 10 weeks group. In the HG 12 weeks group, the number of apoptotic cells were increased by 44.29\% compared with the CTL 12 weeks group.The number of TUNEL positive cells in the HG 12 weeks group 

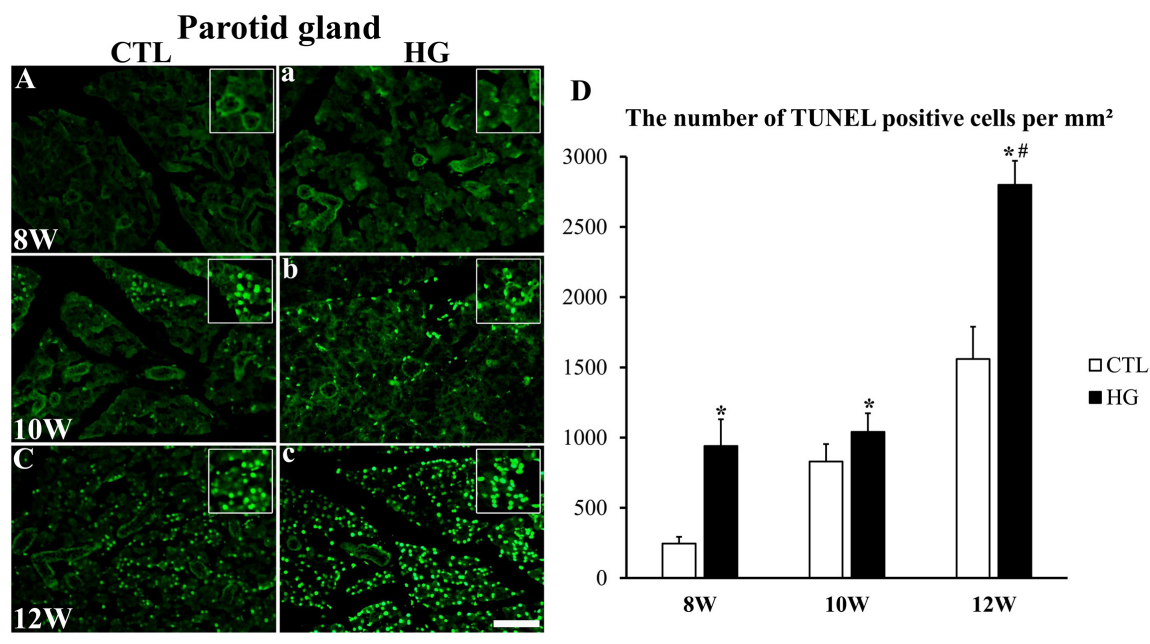

Figure 7. TUNEL stain in the parotid gland of the control and HG groups. 200×. Scale Bar $=100 \mu \mathrm{m}$. (a)-(c) In the HG group, TUNEL positive apoptotic cells are mainly observed in acinar cells of the parotid gland than (A)-(I) in the CTL groups. (D) The number of TUNEL positive cells in the parotid gland of the CTL and HG group. ( $n=7$ per group; ${ }^{\star} P<0.05$, significantly different from the CTL group, ${ }^{\sharp} P<0.05$, significantly different from the pre-adjacent HG group). The bars indicate the means \pm SEM.

Table 2. The number of positive cells $\left(\right.$ cells $\left./ \mathrm{mm}^{2}\right)$ in parotid gland.

\begin{tabular}{cccc}
\hline CTL 8 weeks & $245 \pm 48.088$ & HG 8 weeks & $940 \pm 190.066$ \\
CTL 10 weeks & $830 \pm 124.248$ & HG 10 weeks & $1040 \pm 132.994$ \\
CTL 12 weeks & $1560 \pm 229.538$ & HG 12 weeks & $2800 \pm 170.477$ \\
\hline
\end{tabular}

was also significantly higher than that in the HG 10 weeks group and pre-adjacent group (Figure 7(D)).

\section{Discussion}

There are several causes of xerostomia, due to abnormal decrease in salivation. One of such causes is diabetes [16]. The saliva flow rate in type 2 diabetic patients has been reported to be decreased. Changes in glucose, amylase and immunoglobulin A components in saliva also occur in diabetic patients [17] [18]. In this study, we observed changes in salivary glands by hyperglycemia and emphasis on apoptosis of salivary glands.

In this study, western blot and immunohistochemistry were performed to investigate the effect of hyperglycemia, for a symptom of diabetes, on apoptosis in salivary gland cells by using Fas (cell death receptor), Bax (pro-apoptotic protein activating down-stream of apoptosis signal), and caspase-3 (activating up-stream of apoptosis signal) antibodies [19].

The results of this study, western blots and immunohistochemistry analyses using Fas antibody showed that expression of Fas was high in the HG groups (Figure 2) (Figure 5) (Table 1) (Table 2). These results tend to be consistent with the high expression of Fas in the salivary epithelium of Sjogren's syndrome, 
one of the causes of xerostomia syndrome found in previous studies [20] [21]. The results of this study, Bax antibody also showed high expression in the HG groups, consistent with previous studies reported that salivary glands in patients with Sjogren's syndrome have higher staining intensity of Bax in acinar and duct [22]. The results of this study, western blot using cleaved caspase-3 antibody and immunohistochemistry analysis showed that protein expression and positive cells were increased in the HG groups. This result is consistent with previous study showing activated cleaved caspase- 3 in acinar and ducts of Sjogren's syndrome tissue [23].

Results of experiments using Fas, Bax, and cleaved caspase-3 antibodies showed that most protein expression was observed in the HG 10 weeks group in the submandibular gland and their expression levels were the highest in the HG 12 weeks group in the parotid gland. The mitotic rate of salivary parenchymal cells in rodents occurs once every 1-3 months while the rate of cell division in the parotid gland is two times faster than that in the submandibular gland [24] [25] [26].

TUNEL staining was performed to confirm apoptosis in this study. In the submandibular gland, the higher number of TUNEL positive cells was observed in the HG 10 weeks group. In the parotid gland, the higher number of TUNEL positive cells was observed in the HG 12 weeks group. In both salivary glands, numbers of TUNEL positive cells were increased in the HG group and TUNEL positive cells were more clearly in the parotid gland, consistent with previous findings [27] [28]. Immunohistochemistry and TUNEL staining revealed that apoptosis was mainly observed in acinar cells rather than duct cells, indicating that acinar cells might be more vulnerable to damage than duct cells. Previous study has suggested that acinar cells play an important role in the homeostasis of salivary glands [29], indicating that acinar cell damage has significant effect on salivary gland function.

As a result of TUNEL staining, more TUNEL positive cells in the HG group of the parotid gland were observed than that in the HG group of the submandibular gland. In the HG 8 weeks group, about $82.78 \%$ more TUNEL positive cells were observed in the parotid gland than in the submandibular gland. In the HG 10 weeks group, about $44.71 \%$ more TUNEL positive cells were observed in the parotid gland than in the submandibular gland. In the HG 12 weeks group, about $85.89 \%$ more TUNEL positive cells were observed in the parotid gland than in the submandibular gland.

In the previous study, it was reported that in the presence of DM, the apoptotic response of pancreatic acinar cells is increased [30]. This study suggested that more apoptotic signal molecules were observed in parotid gland than submandibular gland because of the acinar cells of the pancreas are composed of serous cells, similar to the histological structure of the parotid gland [30] [31].

It was confirmed in this study that hyperglycemia, a characteristic of diabetes, causes apoptosis of salivary gland cells. Especially, in the HG 10 weeks group of 
submandibular gland, the amount of expression of Fas, Bax and caspase-3 were highest with each about 9.75 level, about 8.96 level and about 7.88 level. TUNEL positive cells were more increased with $575 \pm 163.936$ cells $/ \mathrm{mm}^{2}$ compared with the CTL groups. In addition, in the HG 12 weeks group of parotid gland, the amount of expression of Fas, Bax and caspase-3 were highest with each about 5.77 level, about 7.02 level and about 14.24 level. TUNEL positive cells were increased more increased with $2800 \pm 170.477$ cells $/ \mathrm{mm}^{2}$ compared with the CTL groups.

The results of this study, apoptosis of salivary gland cells could occur due to hyperglycemic, a characteristic of diabetes. Therefore, it is likely that hyposalivation, complication of diabetes, may occur by the function salivary gland is deteriorated due to apoptosis.

\section{Conclusion}

In summary, hyperglycemia is closely related to apoptosis in parotid gland and submandibular gland. The normal function of salivary gland cells is not achieved due to apoptosis of salivary gland cells. Especially, acinar cells that play important role in the homeostasis of salivary glands can cause many apoptosis reactions by hyperglycemia. Thus, the hyperglycemia, a characteristic of diabetes, may be associated with hyposalivation because it reduces the function of salivary gland cells.

\section{Conflicts of Interest}

The author declares no conflicts of interest regarding the publication of this paper.

\section{References}

[1] American Diabetes Association (2015) 2. Classification and Diagnosis of Diabetes. Diabetes Care, 38, S8-S16. https://doi.org/10.2337/dc15-S005

[2] Moore, P.A., Guggenheimer, J., Etzel, K.R., Weyant, R.J. and Orchard, T. (2001) Type 1 Diabetes Mellitus, Xerostomia, and Salivary Flow Rates. Oral Surgery, Oral Medicine, Oral Pathology, Oral Radiology, and Endodontology, 92, 281-291. https://doi.org/10.1067/moe.2001.117815

[3] Greenspan, D. (1996) Xerostomia: Diagnosis and Management. Oncology (Williston Park, NY), 10, 7-11.

[4] Sreebny, L.M. and Valdini, A. (1988) Xerostomia. Part I: Relationship to Other Oral Symptoms and Salivary Gland Hypofunction. Oral Surgery, Oral Medicine, Oral Pathology, 66, 451-458. https://doi.org/10.1016/0030-4220(88)90268-X

[5] Nanci, A. (1994) Oral Histology. 8th Edition, Pro-ed, Seoul.

[6] Sandberg, G.E., Sundberg, H.E., Fjellstrom, C.A. and Wikblad, K.F. (2000) Type 2 Diabetes and Oral Health: A Comparison between Diabetic and Non-Diabetic Subjects. Diabetes Research and Clinical Practice, 50, 27-34. https://doi.org/10.1016/S0168-8227(00)00159-5

[7] Cutler, L.S., Pinney, H.E., Christian, C. and Russotto, S.B. (1979) Ultrastructural Studies of the Rat Submandibular Gland in Streptozotocin Induced Diabetes Melli- 
tus. Virchows Archiv A, 382, 301-311. https://doi.org/10.1007/BF00430406

[8] Lasisi, T.J. and Fasanmade, A.A. (2012) Salivary Flow and Composition in Diabetic and Non-Diabetic Subjects. Nigerian Journal of Physiological Sciences, 27, 79-82.

[9] Ersteniuk, H., Kotyk, T., Dey, N., Yurakh, O. and Popadynets, O. (2016) Effect of Hyperglycemia on the Excretory Ducts of the Submandibular Gland (Histologic Study). Galician Medical Journal, 23, 21-23. https://doi.org/10.21802/gmj.2016.4.9

[10] Avila, J.L., Grundmann, O., Burd, R. and Limesand, K.H. (2009) Radiation-Induced Salivary Gland Dysfunction Results from p53-Dependent Apoptosis. International Journal of Radiation Oncology Biology Physics, 73, 523-529. https://doi.org/10.1016/j.ijrobp.2008.09.036

[11] Stephens, L.C., Schultheiss, T.E., Price, R.E., Ang, K.K. and Peters, L.J. (1991) Radiation Apoptosis of Serous Acinar Cells of Salivary and Lacrimal Glands. Cancer, 67, 1539-1543.

https://doi.org/10.1002/1097-0142(19910315)67:6<1539::AID-CNCR2820670613>3. $\underline{0 . \mathrm{CO} ; 2-\mathrm{Q}}$

[12] Conner, S., Iranpour, B. and Mills, J. (1970) Alteration in Parotid Salivary Flow in Diabetes Mellitus. Oral Surgery, Oral Medicine, Oral Pathology, 30, 55-59.

https://doi.org/10.1016/0030-4220(70)90011-3

[13] Jung, B.H., Lee, H.S. and Yoo, K.Y. (2017) Study on Changes in Endogenous Stem Cells in the Salivary Gland of Streptozotocin-Induced Diabetic Rats. International Journal of Oral Biology, 42, 99-106. https://doi.org/10.11620/IJOB.2017.42.3.099

[14] Oikawa, J., Ukawa, S., Ohira, H., Kawamura, T., Wakai, K., Ando, M., et al. (2015) Diabetes Mellitus Is Associated with Low Secretion Rates of Immunoglobulin A in Saliva. Journal of Epidemiology, 25, 470-474.

https://doi.org/10.2188/jea.JE20140088

[15] Hummel, K.P., Dickie, M.M. and Coleman, D.L. (1966) Diabetes, a New Mutafton in the Mouse. Science, 153, 1127-1128. https://doi.org/10.1126/science.153.3740.1127

[16] Kao, C.H., Tsai, S.C. and Sun, S.S. (2001) Scintigraphic Evidence of Poor Salivary Function in Type 2 Diabetes. Diabetes Care, 24, 952-953.

https://doi.org/10.2337/diacare.24.5.952-a

[17] Newrick, P.G., Bowman, C., Green, D., O’Brien, I.A.D., Porter, S.R., Scully, C., et al. (1991) Parotid Salivary Secretion in Diabetic Autonomic Neuropathy. Journal of Diabetic Complications, 5, 35-37. https://doi.org/10.2337/diacare.24.5.952-a

[18] Kaufmann, T., Strasser, A. and Jost, P.J. (2012) FAS Death Receptor Signalling: Roles of Bid and XIAP. Cell Death and Differentiation, 19, 42. https://doi.org/10.1038/cdd.2011.121

[19] Sung, J.H., Jeong, M.Y., Eung-Ryoung Lee, H.S.J. and Cho, S.G. (2006) Mitochodrial Proteins in Apoptosis and Neuronal Degeneration. Cancer Prevention Research, 11, 256-263.

[20] Ogawa, N., Shimoyama, K. and Kawanami, T. (2005) Molecular Mechanisms of Salivary Gland Destruction in Patients with Sjogren's Syndrome. Japanese Journal of Clinical Immunology, 28, 10-20. https://doi.org/10.2177/jsci.28.10

[21] Abu-Helu, R.F., Dimitriou, I.D., Kapsogeorgou, E.K., Moutsopoulos, H.M. and Manoussakis, M.N. (2001) Induction of Salivary Gland Epithelial Cell Injury in Sjogren's Syndrome: In Vitro Assessment of T Cell-Derived Cytokines and Fas Protein Expression. Journal of Autoimmunity, 17, 141-153.

https://doi.org/10.1006/jaut.2001.0524 
[22] Kong, L., Ogawa, N., McGuff, H.S., Nakabayashi, T., Sakata, K.M., Masago, R., et al. (1998) Bcl-2 Family Expression in Salivary Glands from Patients with Primary Sjögren's Syndrome: Involvement of Bax in Salivary Gland Destruction. Clinical Immunology and Immunopathology, 88, 133-141. https://doi.org/10.1006/clin.1998.4556

[23] Jimenez, F., Aiba-Masago, S., Al Hashimi, I., Vela-Roch, N., Fernandes, G., Yeh, C.K., et al. (2002) Activated Caspase 3 and Cleaved Poly(ADP-Ribose) Polymerase in Salivary Epithelium Suggest a Pathogenetic Mechanism for Sjögren's Syndrome. Rheumatology, 41, 338-342. https://doi.org/10.1093/rheumatology/41.3.338

[24] Glücksman, A. and Cherry, C.P. (1962) The Induction of Adenomas by the Irradiation of Salivary Glands of Rats. Radiation Research, 17, 186-202. https://doi.org/10.2307/3571308

[25] Cherry, C.P. and Glucksmann, A. (1959) Injury and Repair Following Irradiation of Salivary Glands in Male Rats. The British Journal of Radiology, 32, 596-608. https://doi.org/10.1259/0007-1285-32-381-596

[26] Nagler, R.M. (2002) The Enigmatic Mechanism of Irradiation-Induced Damage to the Major Salivary Glands. Oral Diseases, 8, 141-146. https://doi.org/10.1034/j.1601-0825.2002.02838.x

[27] Muhvic-Urek, M., Bralic, M., Curic, S., Pezelj-Ribaric, S., Borcic, J. and Tomac, J. (2006) Imbalance between Apoptosis and Proliferation Causes Late Radiation Damage of Salivary Gland in Mouse. Physiological Research, 55, 89-95.

[28] Leslie, M.D. and Dische, S. (1994) The Early Changes in Salivary Gland Function during and after Radiotherapy Given for Head and Neck Cancer. Radiotherapy and Oncology, 30, 26-32. https://doi.org/10.1016/0167-8140(94)90006-X

[29] Aure, M.H., Konieczny, S.F. and Ovitt, C.E. (2015) Salivary Gland Homeostasis Is Maintained through Acinar Cell Self-Duplication. Developmental Cell, 33, 231-237. https://doi.org/10.1016/j.devcel.2015.02.013

[30] Gukovskaya, A.S., Gukovsky, I., Jung, Y., Mouria, M. and Pandol, S.J. (2002) Cholecystokinin Induces Caspase Activation and Mitochondrial Dysfunction in Pancreatic Acinar Cells Roles in Cell Injury Processes of Pancreatitis. Journal of Biological Chemistry, 277, 22595-22604. https://doi.org/10.1074/jbc.M202929200

[31] Trulsson, L.M., Svanvik, J., Permert, J. and Gasslander, T. (2001) Cholecystokinin Octapeptide Induces Both Proliferation and Apoptosis in the Rat Pancreas. Regulatory Peptides, 98, 41-48. https://doi.org/10.1016/S0167-0115(00)00223-8 